\title{
Work injuries among migrant workers in Denmark
}

\author{
Karin Biering, ${ }^{1}$ Flemming Lander, ${ }^{2}$ Kurt Rasmussen ${ }^{1}$
}

'Department of Occupational Medicine, Danish Ramazzini Centre, University Research Clinic, Regional Hospital West Jutland, Herning, Denmark ${ }^{2}$ Department of Occupational and Environmental Medicine, Odense University Hospital, Odense, Denmark

\section{Correspondence to}

Dr Karin Biering, Department of Occupational Medicine, Regional Hospital West Jutland, DK-7400 Herning, Denmark; karbie@rm.dk

Received 7 March 2016 Revised 13 June 2016 Accepted 5 July 2016 Published Online First 22 August 2016

\section{SLinked}

http://dx.doi.org/10.1136/ oemed-2016-103964

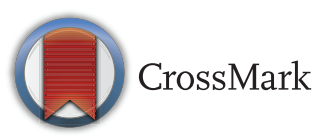

To cite: Biering K, Lander F, Rasmussen K. Occup Environ Med 2017;74:235-242.

\section{ABSTRACT \\ Objectives Work migration into Denmark has}

increased during the recent decades, especially after the enlargement of the European Union (EU) in 2004. Whether or not migrant workers experience more work injuries than the native workforce has been debated and results are conflicting, most likely due to methodological difficulties and cultural disparities. We set out to meet these challenges using population-based work injury registers, targeting a specific and representative region in Denmark.

Methods This population-based study used data on work injuries from an emergency department (ED) and reported injuries from the ED's catchment area to the Danish Working Environment Authority during 11 years. We calculated incidences of work injury for groups of migrant workers compared with native Danes and adjusted incidence rate ratios based on information on the complete working population.

Results The incidences of work injuries among migrant workers from the new EU countries and from the rest of the world were higher compared with Danish workers and workers from the old EU countries and other Western countries. Especially migrants older than 30 years and in low-risk industries were at higher risk. Workers who had migrated recently were at even higher risk.

Conclusions We found increased risk of work injuries among migrant workers. Studying migrants in registers is a methodological challenge as some migrants are not registered, for legal or illegal reasons; thus, only a selected group is studied, but this may most likely underestimate the risk.

\section{INTRODUCTION}

Migration has been known for centuries all over the world, where people have moved to other areas for different reasons and a range of theories have been presented to explain the migration process. ${ }^{1}$ Thus, migration can have origins in everything from poverty and hunger over unemployment to adventurousness. In the literature, distinction between immigrants and migrants is often blurred. Often a distinction is made between immigrants as persons who are or intend to settle in their new country and migrants who are persons with temporary residence. ${ }^{2}$

After the enlargement of the EU starting in 2004 combined with the agreement of free movement of people and labour within the EU member countries, ${ }^{3}$ access to legal work in Denmark has improved, which also includes workers from the new EU member states from Central and Eastern Europe. Since the enlargement, the number of immigrations from these

\section{What this paper adds}

- Work migration is a global tendency and migrant workers may be at increased risk of work injuries.

- Previous studies have been conducted in selected industries and with limited number of workers.

- We found evidence of increased risk, especially in older workers and in low risk industries in a register-based study, as opposed to findings in the native population, where younger workers in high risk industries have increased risk.

- Recent migration increased the risk, suggesting that being new in the job increases the risk.

countries has more than doubled. ${ }^{4}$ However, not all migrants appear in the official census; either because they are commuting, have not registered yet, or because they work illegally. The number of illegal migrants in Denmark has been estimated by use of the capture-recapture estimator, with 50\% replacement per year, to be 32700 persons in 2013, mostly from non-EU countries, ${ }^{5}$ and thus a small group compared with the total number of persons with foreign nationality in Denmark ( 400 000 in 2013). ${ }^{4}$ The additional number of commuters and migrant workers who are not registered is unknown.

Many migrant workers are employed as unskilled workers and, due to their vulnerable life positions, often more willing to work harder, for longer hours and perform unattractive tasks, often referred to as 3D-jobs; 'Dirty, Dangerous and Demanding'. These jobs can be attractive to migrant workers due to unemployment or better payment than equivalent jobs in their home countries. Many of the jobs are in the category of precarious work; often temporary, part-time, with changing employers and high degree of uncertainty in the job. The tasks performed are often hard and unattractive and possibly even more dangerous as well. ${ }^{67}$

Work injuries among migrant workers have been examined all over the world during the past decades. ${ }^{8}$ Besides smaller studies of injury incidences in specific industries or specific groups of national origin, ${ }^{9} 10$ a few studies have compared the rates of work injuries to native workers in specific industries or population based. The studies revealed mixed results as some studies report no difference, ${ }^{11-13}$ while others report increased rates in the migrant population. ${ }^{6} 7$ 14-18 Previous studies were very heterogeneous in design and population, but a common problem was the definition of the 
denominator when calculating the incidences and the lack of adjustment for demographic differences and/or differences in industries. Precise estimation of the denominator is crucial to avoid bias. ${ }^{19}$ The previous literature presents studies with number of workers as the denominator, where time at risk, that is, person-years at risk, is of greater relevance. Also, age differences may bias the results since younger workers and lowseniority workers are known to have higher risk of work injuries. $^{20}$

In Denmark, little is known about the incidence of work injuries among migrant workers. The Danish Working Environment Authority (DWEA) published a report in 2011, where the incidence of injuries over 3 years among different types of workers with foreign nationality was compared with Danish citizens. ${ }^{21}$ Overall, their findings suggested a higher incidence of reported injuries, especially among workers from the European Union (EU) in comparison with native Danes. When comparing the top 10 of the countries contributing the largest absolute numbers of reported injuries, Sweden, Poland, Turkey, Germany, Afghanistan, Iraq and Bosnia-Herzegovina had higher incidences compared with native Danes, while Norway and Great Britain had lower incidences. ${ }^{21}$ However, the results were based on reported injuries only, which may underestimate the true incidence of work-related injuries due to underreporting. ${ }^{22-26}$ Furthermore, the report did not take any differences in demographics and industries into account, but identified industries with higher as well as lower incidences among foreigners in general compared with overall reported incidences. All incidences are calculated with large uncertainties due to the limited sample size.

The aim of this study was to compare the incidence of work injuries among different groups of migrant workers with the native working population by using gathered data from an emergency department (ED) and from reported injuries to the DWEA while taking demographic and industrial differences into account.

\section{MATERIAL AND METHODS \\ Material}

The study comprised data from three different sources from a specific geographic area of Denmark: a population-based register of ED visits, reported injuries to the DWEA and demographic data from Statistics Denmark. All data sources covered the period from 2003 to 2013. A recent Danish study revealed that data from an ED combined with reported data to the authorities actually most likely represent a vast majority of all major work injuries as well as high number of minor injuries. ${ }^{27}$

The area was defined by the catchment area of the ED of Odense University Hospital, which covers a well-defined mixed urban and rural geographical region with $\sim 430000$ inhabitants.

The ED data are consecutively collected for all contacts to the University Hospital Emergency Department, and included provided the injury had occurred during work time. Quality assurance and information technology (IT) systems have been unchanged for the whole period. This particular ED collects data on all visits for research purposes, and the register is thus more detailed and complete than the general national register of injuries. The demographic of the area is comparable with the rest of Denmark.

The DWEA register contains work injuries reported by employers, employees, unions and health staff. In Denmark, it is mandatory for employers to report any work injury causing sick leave at least 1 day more than the date of injury. All reported injuries, which occurred at work sites in the catchment area of the ED between 2003 and 2013, were included. The DWEA register is aimed at compensation claims, but additionally, the reporting system is designed for surveillance of work injuries, and this system is assigned to a special legislation under the board of DWEA.

Injury records from the ED and DWEA were linked to Statistics Denmark, by use of the civil registration number (CPR number) and injury date/year. Each Danish citizen, as well as registered migrant workers, holds a unique CPR number that links each person to demographic and work-related registries. ${ }^{28}$ Migrant workers from EU countries are provided with their CPR number when their employer registers them in the tax system or when they apply for a health card when they move to Denmark and at the latest at 3 months $(6$ months if they are searching for job). Migrant workers from non-European countries obtain their CPR number when they receive their work permit.

Statistics Denmark is the central authority on Danish statistics. Among a range of topics covered by Statistics Denmark, they hold the population register, containing movements within and to/from Denmark and nationality. Statistics Denmark also holds registers of employment and industries, based on registers of employers/companies and taxpayers in Denmark. Norredam et $a l^{29}$ describe the possibilities of using register-based information in studies in the field of health and migration in detail.

In this study, we only included persons with a valid CPR number, as persons without CPR numbers in the ED or DWEA register could not be linked to data from Statistics Denmark. Illegal workers are inherently not holding a CPR number, but the same goes for legal migrant workers, who have been working in Denmark for a short period, who are employed in a foreign company and temporarily posted in Denmark or who commute from another country. When persons without CPR number visit the EDs, they are registered in the database, possibly with the same information as everybody else, but due to language problems, it may not always be possible to retrieve all information, that is, if the injury is work related. Instead of a CPR number, they are registered under a similar number based on their date of birth, gender and initials, but this is not unique for each person and not linked to a correct CPR number even if this is obtained later. Also, in DWEA, registrations are made without a valid CPR number for some employees.

In accordance with the Danish Health Act, all non-residents staying in Denmark are entitled to emergency hospital care free of charge 'in the event of an accident, childbirth, acute illness or sudden aggravation of a chronic disease'. All other healthcare services must be paid for if the person is not holding a CPR number. ${ }^{30} 31$ This implies that migrant workers that are not holding a CPR number are entitled to acute treatment in the ED as any other worker.

\section{Methods}

Data from Statistic Denmark were merged with the data from the ED and DWEA, using the CPR number and date(s) of injury as identifier. We accepted a difference of \pm 7 days between the dates of injury, based on the assumption that these would be related to the same injury. Based on the nationality, we divided the population into the following four nationality groups:

- Native Danes, including people from the Faroe Islands and Greenland

- Old EU (Austria, Belgium, Finland, France, Germany, Greece, Ireland, Italy, Luxembourg, the Netherlands, Portugal, Spain, Sweden, UK plus Iceland, Norway and 
Switzerland) and other Western countries (Northern America, Australia and New Zealand

- New EU (Bulgaria, Croatia, Cyprus, Czech Republic, Estonia, Hungary, Latvia, Lithuania, Malta, Poland, Slovakia and Slovenia)

- (injuries among migrants from the new EU countries were coded in that group from the year after the country's entry in the EU, before that in the group 'other countries')

- Other counties (Asia, Africa, Middle East, South America)

Injuries not registered with a valid CPR number were excluded. These could be migrant workers or commuters from other countries, but could also be native Danes who did not report their CPR number correctly at admission or simple mistyping to the databases. In the ED data set, 1318 injuries were excluded on the basis of one of the above-mentioned reasons, while 1101 injuries were excluded from the DWEA data set.

We dichotomised age at 30 years and divided the study period into two periods: an early from 2003 to 2007 and a late from 2008 to 2013. We categorised all industries based on the Nomenclature of Economic Activities (NACE) into main groups. ${ }^{32}$ Three high-risk sectors (construction, agriculture and transportation) were analysed separately, as opposed to the low-risk sectors (health and social services, public administration, teaching, trade and business, hotels and restaurants, industrial manufacturing, etc). The type of injury was coded into six main groups for descriptive purposes.

\section{Analysis}

The population was described using proportions by nationality groups.

We calculated incidences with 95\% CIs for the complete period for each nationality group. The numerator was the number of injuries in each group in focus, while the denominator was number of person-years in the equivalent group in the workforce. Person-years were calculated separately in all strata, meaning that a person could contribute in different groups for each year, that is, if they changed industry or nationality (became Danish citizens). We further analysed the data with Poisson regression to identify adjusted incidence rate ratios (IRRs). A priori, we expected possible interaction of sex, age, year of injury and high/low-risk industries. We identified interaction of age and high/low-risk industries on the association between nationality and injuries, and analysed the data stratified on these groups and in combined stratifications. We used sex and year of injury as possible confounding variables.

Furthermore, we performed an alternative analysis with a categorisation where only migrants who had a date of entry in Denmark within the past 3 years were placed in their respective country groups; all others were placed together with the native Danes. In the analysis where the categorisation was based on nationality only, the categories may represent possible cultural differences shared within groups of similar countries, while the categorisation based on date of entry may more specifically represent integration into the Danish workforce.

Data were managed and analysed using Stata/MP 13.

\section{RESULTS}

In the study period, the ED had 41448 valid visits related to work injuries, related to 31535 persons. In DWEA, we identified 36484 valid reported work injuries in the study period, related to 32066 persons. We found an overlap of 9993 work injuries recorded in the ED and DWEA, equivalent to $12.8 \%$, when allowing a period of \pm 7 -day slack. The proportion of reported injuries to DWEA among migrants was slightly lower than among the Danes.

Table 1 describes the combined population with injuries. The injuries from the ED and DWEA comprised 65020 from Danes, 865 injuries from migrants from the old EU counties, 460 from the new EU countries and 1594 from the rest of the world-altogether 2919 injuries among migrant workers. Table 2 describes the workforce in the catchment area. The workforce in the area comprised 1850734 person-years of Danes, 26491 person-years of migrants from the old EU countries, 12150 from the new EU countries and 28522 from the rest of the world-altogether 67163 migrant worker person-years.

When combining the two tables, the overall distributions of injuries among migrant workers were to some extent similar to the distribution of migrant workers in the general workforce, although some differences in demographics were present. Injuries were more common among men across nationality, although the workforce comprised more men than women. The gender distribution was even more heterogeneous among migrant workers, but this was not reflected in the injuries as these were relatively in line with the Danish population, except for the group of workers from the rest of the world, where male workers experienced more injuries compared with all other groups. Injuries more often occurred among the younger workers in Danish workers and workers from the old EU, but opposite trend is observed in the workers from the new EU and the rest of the world. The number of migrants has increased during the decade, especially migrants from the new EU and from the rest of the world. The proportions of injuries reflect this increase, except in the group of workers from the rest of the world, where relatively few injuries occurred in the latter half of the period. As expected, high-risk sectors accounted for relatively more accidents, but this was most dominant in Danish workers, while low-risk industries accounted for relatively more injuries among migrant workers. The nature of the injuries was comparable over nationality groups, except for the workers from the rest of the world, where soft tissue injuries and poisoning, cauterisation or burns were more common compared with other types of injuries.

The overall incidence rate of work injuries per 10000 person-years among Danish workers was 348.4 (95\% CI 345.8 to 351.1), and the incidence among the old EU and Western workers was 323.5 (95\% CI 302.0 to 345.1); for the new EU workers, it was 374.8 (95\% CI 340.6 to 409.1 ) and for workers from other countries, it was 547.9 (95\% CI 521.0 to 574.8 ).

When comparing the different groups of migrant workers with Danish workers, we identified several differences expressed by crude IRR as well as IRR adjusted for sex and calendar years (table 3). Workers from the rest of the world had increased risk ratio of work injuries compared with Danish workers, while workers from the old EU and other Western countries had a lower risk. Workers from the new EU countries had a slightly higher risk. Adjustment for sex and calendar year increased the estimates only slightly. When stratifying into younger versus older workers, we found that older migrant workers from the new EU and rest of the world had an increased risk compared with older workers from Denmark and the old EU. Stratifying into high-risk versus low-risk sectors showed that migrant workers from the new EU and the rest of the world occupied in low-risk sectors had higher risk of injuries compared with Danes and workers from the old EU and opposite in the highrisk sectors. Combining these stratifications revealed a nearly twofold increased risk for migrant workers from the new EU 
Table 1 Description of the injuries ( $n=67443$ injuries)

\begin{tabular}{|c|c|c|c|c|c|c|c|c|}
\hline \multirow[b]{2}{*}{ Description by nationality group } & \multicolumn{2}{|l|}{ Danish } & \multicolumn{2}{|c|}{ Old EU } & \multicolumn{2}{|c|}{ New EU } & \multicolumn{2}{|l|}{ Other } \\
\hline & $\mathbf{n}$ & Per cent & $\mathbf{n}$ & Per cent & $\mathbf{n}$ & Per cent & $\mathbf{n}$ & Per cent \\
\hline Total & 65020 & 95.7 & 865 & 1.3 & 460 & 0.7 & 1594 & 2.4 \\
\hline \multicolumn{9}{|l|}{ Gender } \\
\hline Male & 44625 & 68.6 & 621 & 71.8 & 312 & 67.8 & 1220 & 76.5 \\
\hline Female & 20395 & 31.4 & 244 & 28.2 & 148 & 32.2 & 374 & 23.5 \\
\hline \multicolumn{9}{|l|}{ Age } \\
\hline$\leq 30$ years & 20274 & 31.2 & 181 & 20.9 & 201 & 43.7 & 677 & 42.5 \\
\hline$>30$ years & 44746 & 68.8 & 684 & 79.1 & 259 & 56.3 & 917 & 57.5 \\
\hline \multicolumn{9}{|l|}{ Period of injury } \\
\hline 2003-2007 & 32912 & 50.6 & 379 & 43.8 & 107 & 23.3 & 763 & 47.9 \\
\hline 2008-2013 & 32108 & 49.4 & 486 & 56.2 & 353 & 76.7 & 831 & 52.1 \\
\hline \multicolumn{9}{|l|}{ Sector } \\
\hline High risk* & 14984 & 23.1 & 157 & 18.2 & 103 & 22.4 & 216 & 13.6 \\
\hline Low risk & 50036 & 76.9 & 708 & 81.8 & 357 & 77.6 & 1378 & 86.4 \\
\hline \multicolumn{9}{|l|}{ Nature of injury } \\
\hline Amputations and fractures & 4973 & 7.7 & 72 & 8.3 & 49 & 10.7 & 90 & 5.7 \\
\hline Sprains & 16270 & 24.9 & 213 & 24.6 & 84 & 18.3 & 277 & 17.4 \\
\hline Wounds & 23807 & 36.6 & 303 & 35.0 & 189 & 41.0 & 683 & 42.9 \\
\hline Soft tissue injuries & 4033 & 6.2 & 53 & 6.1 & 25 & 5.4 & 123 & 7.7 \\
\hline Poisoning, cauterisation or burns & 1886 & 2.9 & 27 & 3.1 & 16 & 3.5 & 83 & 5.2 \\
\hline Miscellaneous injuries & 14151 & 21.8 & 197 & 22.8 & 97 & 21.1 & 338 & 21.2 \\
\hline
\end{tabular}

*High-risk sectors were construction, agriculture and transportation.

EU, European Union.

and the rest of the world in the group of older workers in low-risk sectors.

The alternative risk analysis where only workers who had been in Denmark for $<3$ years were defined as migrants showed that all types of migrants had higher incidences compared with Danes and migrants who had been in Denmark for $>3$ years (table 4). The results with higher risk in older migrant workers and in migrant workers in low-risk sectors were also stronger in the alternative analysis.

\section{DISCUSSION}

We found that migrant workers from the new EU countries and especially from the non-Western world had increased risk of work injuries compared with Danish workers and workers from the Western countries including the old EU countries. While this risk was only marginally higher, stratifications with respect to age groups and high-risk versus low-risk sectors showed that especially migrants older than 30 years and migrant workers in low-risk sectors from the new EU countries and the non-Western world had a more pronounced increased risk of work injuries.

The analysis on migrants who had been in Denmark for $<3$ years enhanced all findings and even found that workers from the old EU countries and from other Western countries were at increased risk.

When studying migrant workers, an inevitable problem is to get hold of the relevant population. ${ }^{19}$ In the native Danish population, using the two sources of data of work injuries will cover most injuries, ${ }^{26}$ but this is most likely not the situation for

Table 2 Description of the workforce in the area ( $n=1917897$ person-years)

\begin{tabular}{|c|c|c|c|c|c|c|c|c|}
\hline \multirow[b]{2}{*}{ Description by nationality group } & \multicolumn{2}{|l|}{ Danish } & \multicolumn{2}{|l|}{ Old EU } & \multicolumn{2}{|c|}{ New EU } & \multicolumn{2}{|l|}{ Other } \\
\hline & $\mathbf{n}$ & Per cent & $\mathbf{n}$ & Per cent & $\mathbf{n}$ & Per cent & $\mathbf{n}$ & Per cent \\
\hline Total & 1850734 & 96.5 & 26491 & 1.4 & 12150 & 0.6 & 28522 & 1.5 \\
\hline \multicolumn{9}{|l|}{ Gender } \\
\hline Male & 972841 & 52.6 & 15299 & 57.7 & 6393 & 52.6 & 15649 & 54.9 \\
\hline Female & 877893 & 47.4 & 11192 & 42.3 & 5757 & 47.4 & 12873 & 45.1 \\
\hline \multicolumn{9}{|l|}{ Age } \\
\hline$\leq 30$ years & 472194 & 25.5 & 6710 & 25.3 & 6538 & 53.8 & 12212 & 46.7 \\
\hline$>30$ years & 1378540 & 74.5 & 19781 & 74.7 & 5612 & 46.2 & 15209 & 53.3 \\
\hline \multicolumn{9}{|l|}{ Period of observation } \\
\hline $2003-2007$ & 855905 & 46.3 & 11134 & 42.0 & 2323 & 19.1 & 11432 & 40.1 \\
\hline 2008-2013 & 994829 & 53.7 & 15357 & 58.0 & 9827 & 80.9 & 17090 & 59.9 \\
\hline \multicolumn{9}{|l|}{ Sector } \\
\hline High risk* & 277027 & 15.0 & 2537 & 9.6 & 4134 & 34.0 & 5176 & 18.2 \\
\hline Low risk & 1573707 & 85.0 & 23954 & 90.4 & 8016 & 66.0 & 23346 & 81.8 \\
\hline
\end{tabular}

*High-risk sectors were construction, agriculture and transportation.

EU, European Union. 
Table 3 Risk of work injuries in Danish and migrant workers based on nationality

\begin{tabular}{|c|c|c|c|c|c|c|c|c|}
\hline \multirow[b]{2}{*}{ All } & \multicolumn{2}{|l|}{ IRR } & \multicolumn{6}{|l|}{ IRR } \\
\hline & Crude & $95 \% \mathrm{Cl}$ & Adjusted* & $95 \% \mathrm{Cl}$ & & & & \\
\hline Danish & 1.00 & & 1.00 & & & & & \\
\hline Old EU and Western & 0.93 & (0.87 to 1.00$)$ & 0.90 & (0.85 to 0.97$)$ & & & & \\
\hline New EU & 1.08 & (0.98 to 1.18 ) & 1.13 & (1.02 to 1.24$)$ & & & & \\
\hline Other & 1.57 & (1.50 to 1.65$)$ & 1.56 & (1.48 to 1.64$)$ & & & & \\
\hline \multirow[t]{3}{*}{ Age stratifications } & \multicolumn{2}{|c|}{$\leq 30$ years } & \multicolumn{2}{|l|}{$>30$ years } & & & & \\
\hline & IRR & $95 \% \mathrm{Cl}$ & IRR & $95 \% \mathrm{Cl}$ & & & & \\
\hline & \multicolumn{2}{|c|}{ Adjusted* ${ }^{*}$} & \multicolumn{2}{|l|}{ Adjusted* } & & & & \\
\hline Danish & 1.00 & & 1.00 & & & & & \\
\hline Old EU and Western & 0.67 & (0.58 to 0.77$)$ & 1.02 & (0.94 to 1.10$)$ & & & & \\
\hline New EU & 0.74 & (0.65 to 0.86$)$ & 1.49 & (1.32 to 1.68$)$ & & & & \\
\hline Other & 1.12 & (1.04 to 1.21 ) & 1.86 & (1.74 to 1.98$)$ & & & & \\
\hline \multirow[t]{3}{*}{ Sector stratifications } & \multicolumn{2}{|c|}{ High riskt } & \multicolumn{2}{|l|}{ Low risk } & & & & \\
\hline & IRR & $95 \% \mathrm{Cl}$ & IRR & $95 \% \mathrm{Cl}$ & & & & \\
\hline & \multicolumn{2}{|c|}{ Adjusted* } & \multicolumn{2}{|l|}{ Adjusted* } & & & & \\
\hline Danish & 1.00 & & 1.00 & & & & & \\
\hline Old EU and Western & 1.15 & (0.98 to 1.34 ) & 0.89 & (0.83 to 0.96 ) & & & & \\
\hline New EU & 0.56 & (0.46 to 0.68$)$ & 1.45 & (1.30 to 1.61$)$ & & & & \\
\hline Other & 0.87 & (0.76 to 0.99$)$ & 1.78 & (1.69 to 1.88 ) & & & & \\
\hline \multirow[t]{3}{*}{$\begin{array}{l}\text { Combined } \\
\text { stratifications }\end{array}$} & \multicolumn{2}{|c|}{$\begin{array}{l}\text { Age } \leq 30 \text { years and } \\
\text { high riskt }\end{array}$} & \multicolumn{2}{|c|}{$\begin{array}{l}\text { Age }>30 \text { years and } \\
\text { high riskt }\end{array}$} & \multicolumn{2}{|c|}{$\begin{array}{l}\text { Age } \leq 30 \text { years and } \\
\text { low risk }\end{array}$} & \multicolumn{2}{|c|}{$\begin{array}{l}\text { Age }>30 \text { years and } \\
\text { low risk }\end{array}$} \\
\hline & IRR & $95 \% \mathrm{Cl}$ & IRR & $95 \% \mathrm{Cl}$ & IRR & $95 \% \mathrm{Cl}$ & IRR & $95 \% \mathrm{Cl}$ \\
\hline & \multicolumn{2}{|c|}{ Adjusted* } & \multicolumn{2}{|l|}{ Adjusted* } & \multicolumn{2}{|c|}{ Adjusted* } & \multicolumn{2}{|c|}{ Adjusted* } \\
\hline Danish & 1.00 & & 1.00 & & 1.00 & & 1.00 & \\
\hline Old EU and Western & 0.96 & (0.69 to 1.34 ) & 1.28 & (1.07 to 1.53 ) & 0.66 & (0.56 to 0.77$)$ & 1.00 & (0.92 to 1.08$)$ \\
\hline New EU & 0.36 & (0.28 to 0.47$)$ & 0.74 & (0.55 to 0.99 ) & 1.00 & (0.85 to 1.18 ) & 1.81 & (1.58 to 2.07 ) \\
\hline Other & 0.48 & (0.39 to 0.58$)$ & 1.38 & (1.14 to 1.67$)$ & 1.42 & (1.31 to 1.54$)$ & 1.98 & (1.85 to 2.13 ) \\
\hline
\end{tabular}

non-Danish workers. First, in our study, we used the CPR number to identify the population; consequently, we would leave out illegal migrant workers and workers who are working in Denmark legally, but for various reasons have not obtained their CPR number yet. Second, the injury data contained also information on some patients without CPR number $(<4 \%)$ that were most likely migrant workers, but could also be native Danes, not able to provide their CPR number; however, in the latter situation, it should be recoded to the correct number later. It could also be simple mistyping of the number. Third, the overlap of \pm 7 days used for the merging of the two injury data sets could have underestimated the number of events, if employees actually had more than one injury within a week, but this is most likely not related to nationality and may thus only impose possible non-differential misclassification. Finally, especially illegal migrant workers visiting the ED may try to hide that the injury happened while working, if they fear that the ED staff might report them. ${ }^{33}$ Under-reporting of work injuries due to language problems may also cause an underestimation of the true incidence in the ED, and a lack of knowledge to the reporting system in DWEA may play a role as well. In Denmark, reporting to DWEA was previously found related to age, namely that older workers report more injuries while younger workers had relatively more visits to the ED. ${ }^{22}$ In this study, this tendency was also found, and the proportions were comparable in Danish workers and migrant workers (data not shown). Since the migrant workforce is generally younger than the native Danish workforce, it may simply be related to the general association between age and reporting. Another explanation could be that migrants fear more for dismissal by reporting an injury compared with native Danes. All these precautions may most likely cause an underestimation of the incidences and the IRRs, but the combination of the data sources provides the best possible basis for quantitative analysis in this field.

The categorisation into nationality groups relies on the assumption that countries within each group are comparable with each other and different from countries in the other categories when it comes to work and safety culture. This is a major generalisation as differences within each category may be large and important. A choice of categorisation was necessary for the analysis, and placing all migrants into one single category would imply that important differences between categories could have been overlooked. 
Table 4 Risk of work injuries in Danish and migrant workers based on migration within 3 years

\begin{tabular}{|c|c|c|c|c|c|c|c|c|}
\hline \multirow[b]{2}{*}{ All } & \multicolumn{2}{|l|}{ IRR } & \multicolumn{6}{|l|}{ IRR } \\
\hline & Crude & $95 \% \mathrm{Cl}$ & Adjusted* & $95 \% \mathrm{Cl}$ & & & & \\
\hline Danisht & 1.00 & & 1.00 & & & & & \\
\hline Old EU and Western & 1.34 & (1.24 to 1.46 ) & 1.29 & (1.19 to 1.40$)$ & & & & \\
\hline New EU & 1.32 & (1.20 to 1.48$)$ & 1.33 & (1.20 to 1.47$)$ & & & & \\
\hline Other & 2.87 & (2.67 to 3.08 ) & 2.72 & (2.54 to 2.92 ) & & & & \\
\hline \multirow[t]{3}{*}{ Age stratifications } & \multicolumn{2}{|c|}{$\leq 30$ years } & \multicolumn{2}{|l|}{$>30$ years } & & & & \\
\hline & IRR & $95 \% \mathrm{Cl}$ & IRR & $95 \% \mathrm{Cl}$ & & & & \\
\hline & \multicolumn{2}{|c|}{ Adjusted* } & \multicolumn{2}{|l|}{ Adjusted* } & & & & \\
\hline Danisht & 1.00 & & 1.00 & & & & & \\
\hline Old EU and Western & 0.83 & (0.70 to 1.00$)$ & 1.52 & (1.39 to 1.67 ) & & & & \\
\hline New EU & 0.82 & (0.70 to 1.95 ) & 2.05 & (1.77 to 2.37 ) & & & & \\
\hline Other & 1.50 & (1.35 to 1.67 ) & 4.49 & (4.09 to 4.92 ) & & & & \\
\hline \multirow[t]{3}{*}{ Sector stratifications } & \multicolumn{2}{|c|}{ High risk‡ } & \multicolumn{2}{|l|}{ Low risk } & & & & \\
\hline & IRR & $95 \% \mathrm{Cl}$ & IRR & $95 \% \mathrm{Cl}$ & & & & \\
\hline & \multicolumn{2}{|c|}{ Adjusted* } & \multicolumn{2}{|l|}{ Adjusted* } & & & & \\
\hline Danisht & 1.00 & & 1.00 & & & & & \\
\hline Old EU and Western & 1.39 & (1.13 to 1.72$)$ & 1.32 & (1.21 to 1.44$)$ & & & & \\
\hline New EU & 0.60 & (0.48 to 0.75 ) & 1.83 & (1.62 to 2.06 ) & & & & \\
\hline Other & 0.94 & (0.78 to 1.13 ) & 3.70 & (3.43 to 3.99 ) & & & & \\
\hline \multirow[t]{3}{*}{$\begin{array}{l}\text { Combined } \\
\text { stratifications }\end{array}$} & \multicolumn{2}{|c|}{$\begin{array}{l}\text { Age } \leq 30 \text { years and } \\
\text { high risk } \neq\end{array}$} & \multicolumn{2}{|c|}{$\begin{array}{l}\text { Age }>30 \text { years and } \\
\text { high risk } \neq\end{array}$} & \multicolumn{2}{|c|}{$\begin{array}{l}\text { Age } \leq 30 \text { years and } \\
\text { low risk }\end{array}$} & \multicolumn{2}{|c|}{$\begin{array}{l}\text { Age }>30 \text { years and } \\
\text { low risk }\end{array}$} \\
\hline & IRR & $95 \% \mathrm{Cl}$ & IRR & $95 \% \mathrm{Cl}$ & IRR & $95 \% \mathrm{Cl}$ & IRR & $95 \% \mathrm{Cl}$ \\
\hline & \multicolumn{2}{|c|}{ Adjusted* } & \multicolumn{2}{|l|}{ Adjusted* } & \multicolumn{2}{|c|}{ Adjusted* } & \multicolumn{2}{|c|}{ Adjusted* } \\
\hline Danisht & 1.00 & & 1.00 & & 1.00 & & 1.00 & \\
\hline Old EU and Western & 0.90 & (0.57 to 1.41 ) & 1.67 & (1.33 to 2.11$)$ & 0.87 & (0.71 to 1.05 ) & 1.53 & (1.39 to 1.70$)$ \\
\hline New EU & 0.40 & (0.31 to 0.53 ) & 0.78 & (0.54 to 1.14$)$ & 1.13 & (0.94 to 1.35 ) & 2.74 & (2.34 to 3.21 ) \\
\hline Other & 0.45 & (0.35 to 0.59$)$ & 2.54 & (1.92 to 3.35$)$ & 2.38 & (2.11 to 2.68 ) & 5.02 & (4.55 to 5.54 ) \\
\hline
\end{tabular}

Calculations of incidences require a precise denominator, which is completely unknown in the population without CPR number. Also, some of the injuries may be related to other industries than the person's main industry, such as students in spare-time jobs or workers with secondary jobs. When defining the workforce, we took only workers' primary affiliation to industry in each year into account. This may have caused some misclassification of the industries, but this is most likely not related to nationality and thus does not cause bias in the risk estimates. However, the categorisation into broad industry groups may have caused information bias, if migrant workers hold the most dangerous job types and perform the most dangerous tasks within the same industry compared with Danish workers. This could explain the higher risk for migrant workers in low-risk industries compared with native Danes.

Although the population covered 11 years, there were some sample size problems regarding possible subgroup analyses. Ideally, results should be stratified on/adjusted for exact nationality, gender, age, seniority in the job, years since immigration and exact industry, all factors presumably related to work injuries. This would have caused extremely small strata, and thus not possible, but one should keep these disparities in mind when interpreting the results.

Another issue in research among migrant workers relates to the initial motivation for migration; workers who choose to migrate are most likely different from workers who remain in their homeland. ${ }^{18}$ They may differ demographically as typically younger workers have not yet settled with families. In this study, a larger proportion of migrants are under 30 years of age compared with Danish workers. Also, they may be more willing to work hard for a period for additional economic benefits. The migrants may have longer working hours and work more days a week and they may be willing to do unattractive tasks. This may explain why migrant workers in low-risk sectors in general had more injuries than Danish workers, as they may perform the most dangerous tasks that are present even in low-risk sectors. Paradoxically, no increased risk was observed among young migrants, especially not in high-risk jobs as known in the Danish workforce. The reason for this result is basically unknown, but might partly be related to underreporting issues among migrant workers combined with continuously safety campaigns and high political attention by DWEA on these high 
risk sectors during the time after the 2004 EU enlargement, which of cause have been in benefit for all workers and not only Danish workers. Further, especially young migrants may differ from Danish workers with respect to unmeasured characteristics -for instance, characteristics that may be analogous to the healthy worker bias, ${ }^{34}$ where mainly the healthiest and most resourceful workers migrate and get a better job abroad, while the most vulnerable workers may tend to stay in their home country. These differences related to the motivation to migrate are immeasurable in this design, but might add to the understanding of the observed lower injury incidences in the high-risk industries among young migrant workers compared with Danes.

Legal migrants share the same social benefits as the native population, which has recently caused public debate in Denmark about the costs related to migrant workers. However, a recent analysis on the use of healthcare showed that compared with native Danes, Eastern European migrants use the general practice on average only half as often as native Danes, even after adjustment for demographic differences. ${ }^{35}$ This supports the healthy worker effect theory that migrant workers are healthier than their fellow citizens who are still in the home country or the fact that migrant workers prefer to use the health system in their home country and travel back in case of illness or the limitation of use of the Danish health system, if they do not have a CPR number yet. ${ }^{31}$ The latter may also be the case in treatment of minor injuries. These differences may contribute to a possible underestimation of the associations found.

To our knowledge, this is the first study that compared work injuries among migrant workers with the complete native workforce across sectors. The most important strength of this study was the population-based approach, including almost all work injuries in a specific geographic area along with the possibility to calculate the denominator with actual time at risk in the analysis. This is seldom possible in occupational injury research, and this is to our knowledge the first study regarding migrant workers with this possibility. The findings are comparable with previous international research, suggesting an increased risk of injuries among migrant workers. ${ }^{6} 7^{14-18}$

We were to some extent able to reproduce the findings from the report from DWEA, ${ }^{21}$ with a higher occurrence among migrants. In the report, DWEA uses only nationality and not date of entry to define non-Danes, and this implies that persons who have been living in Denmark for decades were classified as non-Danes, as they have retained their homeland nationality. This is comparable with our results presented in table 3 . On the other hand, this could have underestimated higher incidences among migrant workers as the risk related to be new in the Danish workforce could be diluted. We analysed the data using both approaches: based on nationality alone and based on date of entry within 3 years. However, it is unknown if the limit of 3 years' stay in Denmark is suitable, or a longer or shorter period is more appropriate, to define integration into the workforce. The latter approach showed that migrants who are new in the Danish workforce are at higher risk than Danish workers and migrants who have had time to integrate into the Danish work culture and learn safety regulations and the language in general. The risk was higher for migrants from outside EU and other Western countries, suggesting that different work culture -including safety culture-in different parts of the world may also pay a role.

Given the above-mentioned internal limitations and strengths, the overall findings of this study are most likely representative of the current labour market in Denmark and probably also representative of other countries with comparable patterns of migration and workforce and safety regulations, such as many old EU member states.

\section{CONCLUSION}

We found higher risk of work injuries among migrant workers from the new EU countries and from the rest of the world compared with Danish workers. Migrant workers from the old EU countries and other Western countries were comparable with Danish workers. Migrants over 30 years of age and migrants in low-risk sectors were at the highest risk, and migrants who had moved to Denmark recently were at increased risk. Paradoxically, no expected increased risk was observed among young migrants, nor in high-risk jobs, both well-known risk factors in safety research. A possible explanation may partly be related to under-reporting issues, selection in terms of healthy worker bias and high political attention by DWEA on these high-risk industries. Methodological challenges in the registration of migrants pose a challenge to the validity of the results, but may most likely underestimate the findings.

Acknowledgements Hospital-based injury data were kindly supplied by the Accident Analysis Group, Department of Orthopaedics, Odense University Hospital (http://www.ouh.dk/uag). Data on the reported injuries were kindly supplied by DWEA.

Contributors KB designed the study, managed and analysed the data, interpreted the results and drafted and revised the manuscript. FL analysed the data, interpreted the results and revised and approved the manuscript. KR interpreted the results and revised and approved the manuscript.

Funding The Danish Working Environment Research Fund funded this study (grant number 20120221306).

Competing interests None declared.

Ethics approval The Danish Data Protection Agency.

Provenance and peer review Not commissioned; externally peer reviewed.

\section{REFERENCES}

1 Castles S, Miller MJ. The age of migration. 3. ed., revised and updated ed. Basingstoke: Palgrave Macmillan, 2003.

2 Anderson B, Blinder S. Who counts as a migrant? Definitions and their consequences. 3rd rev. UK: Migration Observatory Briefing, COMPAS, University of Oxford, 2014

3 European Union. Article 45: Freedom of movement and of residence. 2004, 2015 http://www.europarl.europa.eu/comparl/libe/elsj/charter/art45/default_en.htm

4 Statistics Denmark. Population. Available at: http://www.dst.dk/HomeUK.aspx

5 Tranæs T, Jensen B. [The illegal migration to Europe-and Denmark: causes, extent and significance]. Kbh.: Gyldendal; The Rockwool Foundation Research Unit, 2014.

6 Richardson DB, Loomis D, Bena J, et al. Fatal occupational injury rates in southern and non-southern States, by race and Hispanic ethnicity. Am J Public Health 2004;94:1756-61.

7 Dong $X$, Platner JW. Occupational fatalities of Hispanic construction workers from 1992 to 2000. Am J Ind Med 2004;45:45-54.

8 Ahonen EQ, Benavides FG, Benach J. Immigrant populations, work and health--a systematic literature review. Scand J Work Environ Health 2007;33:96-104.

9 Wang S, Myers JR, Layne LA. Injuries to hired crop workers in the United States: a descriptive analysis of a national probability survey. Am J Ind Med 2011:54:734-47.

10 Villarejo D, McCurdy SA, Bade BIII, et al. The health of California's immigrant hired farmworkers. Am J Ind Med 2010;53:387-97.

11 Benavides FG, Ahonen EQ, Bosch C. Risk of occupational injury in foreign workers in Spain [2003 and 2004]. Gac Sanit 2008;22:44-7.

12 Nuwayhid I, Fayad R, Tamim H, et al. Work-related injuries in Lebanon: does nationality make a difference? Am J Ind Med 2003;44:172-81.

13 Wu TN, Liou SH, Hsu CC, et al. Epidemiologic study of occupational injuries among foreign and native workers in Taiwan. Am J Ind Med 1997:31:623-30.

14 Ahonen EQ, Benavides FG. Risk of fatal and non-fatal occupational injury in foreign workers in Spain. J Epidemiol Community Health 2006:60:424-6.

15 Corvalan CF, Driscoll TR, Harrison JE. Role of migrant factors in work-related fatalities in Australia. Scand J Work Environ Health 1994;20:364-70. Oct. 
16 McCurdy SA, Samuels SJ, Carroll DJ, et al. Agricultural injury in California migrant Hispanic farm workers. Am J Ind Med 2003;44:225-35.

17 Marchiori L, Marangi G, Mazzoccoli P, et al. A procedure for estimating the rate of occupational accidents in non-European-Union workers with irregular immigrant status. Med Lav 2008;99(Suppl 1):76-87.

18 Egger M, Minder CE, Smith GD. Health inequalities and migrant workers in Switzerland. Lancet 1990;336:816.

19 Richardson D, Loomis D, Bailer AJ, et al. The effect of rate denominator source on US fatal occupational injury rate estimates. Am J Ind Med 2004;46:261-70.

20 Rasmussen $\mathrm{K}$, Hansen $\mathrm{CD}$, Nielsen KJ, et al. Incidence of work injuries amongst Danish adolescents and their association with work environment factors. Am J Ind Med 2011:54:143-52.

21 The Danish Working Environment Authority. [Reported working Accidents 2006-11. The Danish Working Environment Authority yearly Report], 2011.

22 Lander $\mathrm{F}$, Nielsen KJ, Rasmussen $\mathrm{K}$, et al. Patterns of work injuries: cases admitted to emergency room treatment compared to cases reported to the Danish Working Environment Authority during 2003-2010. Occup Environ Med 2014;71:97-103.

23 Leigh JP, Marcin JP, Miller TR. An estimate of the U.S. Government's undercount of nonfatal occupational injuries. J Occup Environ Med 2004:46:10-18.

24 Dong XS, Fujimoto $A$, Ringen $\mathrm{K}$, et al. Injury underreporting among small establishments in the construction industry. Am J Ind Med 2011;54:339-49.

25 Fan ZJ, Bonauto DK, Foley MP, et al. Underreporting of work-related injury or illness to workers' compensation: individual and industry factors. J Occup Environ Med 2006:48:914-22.
26 van Charante AW, Mulder PG. Reporting of industrial accidents in The Netherlands. Am J Epidemiol 1998;148:182-90.

27 Lander F, Nielsen KJ, Rasmussen K, et al. Underreporting of work injuries-a point of view (in Danish, English summary). The Danish Confederation of Trade Unions, 2015.

28 Schmidt M, Pedersen L, Sorensen HT. The Danish Civil Registration System as a tool in epidemiology. Eur J Epidemiol 2014;29:541-9.

29 Norredam M, Kastrup M, Helweg-Larsen K. Register-based studies on migration, ethnicity, and health. Scand J Public Health 2011;39(7 Suppl):201-5.

30 The Danish Health and Medicines Authority. The Danish Health Act. 2014, 2015. http://sundhedsstyrelsen.dk/en/about-us/targets-and-tasks/legislation

31 Aabenhus R, Hallas P. The Danish Health Act and health-care services to undocumented migrants. Ugeskr Laeg 2012;174:2216-19.

32 Eurostat. Statistical Classification of Economic Activities in the European Community, Rev. 2 (2008). 2008. 2015. http://ec.europa.eu/eurostat/ramon/nomenclatures/index. cfm?TargetUrl=LST_NOM_DTL\&StrNom=NACE_REV2\&StrLanguageCode=EN\& IntPcKey=\&StrLayoutCode=HIERARCHIC

33 Biswas D, Toebes B, Hjern A, et al. Access to health care for undocumented migrants from a human rights perspective: a comparative study of Denmark, Sweden, and The Netherlands. Health Hum Rights 2012;14:49-60.

34 Rothman KJ, Greenland S, Lash TL. Modern epidemiology. 3rd edn. Philadelphia: Lippincott Williams \& Wilkins, 2008.

35 Jakobsen KT. [Migrants from Eastern European countries use the general practitioner the least]. Kraka, 2014. 